\title{
Synthesis and Properties of a Polycarboxylate Superplasticizer with a Jellyfish-Like Structure Comprising Hyperbranched Polyglycerols
}

\author{
Manuel Ilg and Johann Plank*(i) \\ Chair for Construction Chemistry, Technische Universität München, Lichtenbergstraße 4, Garching 85748, Germany
}

Supporting Information

\begin{abstract}
Polycarboxylate superplasticizers (PCEs) are comb-shaped polymers with an anionic backbone and several nonionic pendant chains, which typically are comprised of polyethylene glycols. In this study, the synthesis of a new type of superplasticizer is presented, which does not exhibit the typical comb-shaped form of PCEs but is built up from a linear polyetheramine and a hyperbranched polyglycerol scaffold, which was carboxymethylated in the periphery. ${ }^{1} \mathrm{H} /{ }^{13} \mathrm{C}$ NMR and FT-IR spectroscopy and size exclusion chromatography were employed for the characterization of the polymers. Furthermore, their dispersing performance and "slump retention" capability were investigated in cement pastes. Adsorption and zeta potential measurements as well as heat flow calorimetry were conducted to gain more insight into the interaction of the polymers with cement. It was found that such non-comb-shaped polymers are highly effective cement dispersants. Moreover, the hyperbranched superplasticizers exhibited high robustness toward alkali sulfates and maintained the fluidity much longer, compared to a conventional combshaped PCE.
\end{abstract}

\section{INTRODUCTION}

Polycarboxylate superplasticizers (PCEs) emerged as one of the most important superplasticizers for concrete due to their superior performance. ${ }^{1,2}$ Compared to other products like polycondensates, they fluidize cement even at low water to cement ratios, require relatively low dosages, and exhibit a long slump retention capability. ${ }^{3-5}$ The high dispersing efficacy of PCEs can be ascribed to the nonionic side chains, which stretch out into the pore solution and act as a steric barrier to keep the cement particles apart. ${ }^{6}$ Moreover, due to the adsorption of the PCEs, a negative surface charge is induced, which also provokes electrostatic repulsion between cement particles. ${ }^{7}$ However, a key parameter for effective dispersion represents the adsorbed layer thickness of the PCEs on the cement surface. $^{8-10}$ According to the Ottewill Walker equation, a high steric stabilization of particulate suspensions especially can be achieved by polymers which adsorb by forming a particularly thick layer. ${ }^{11}$ Therefore, it is assumed that bulky, outstretched, and sterically demanding polymers might produce an even stronger steric effect than comb-shaped PCEs. This hypothesis was confirmed by Liu et al., who showed that star-shaped PCEs are superior over comb-shaped analogues due to their multi-arm structure composed of acrylic acid-co-isoprenyloxy polyethylene glycol ether (IPEG), which allows the polymer to reach out far more into the pore solution, thus creating a higher layer thickness. ${ }^{12}$ Similar results were also reported for PCEs with a branched topological structure synthesized by free radical copolymerization of acrylic acid, polyethylene glycol methallyl ether (HPEG), and a branched monomer, which was prepared in a two-step synthesis from diallylamine, methyl acrylate, and trimethylolpropane. ${ }^{13}$ Even the incorporation of branched lateral chains into comb-shaped PCEs can effectuate a higher steric hindrance effect as was demonstrated by $\mathrm{Li}$ and co-workers. ${ }^{14}$ They found that the dispersing performance of IPEG-PCEs was considerably improved after the introduction of hyperbranched polyamidoamine side chains synthesized from ethylene diamine and methyl acrylate. All these previous findings suggest that branched structures seem to be very beneficial for the steric stabilization, which is why such motifs are attractive elements for the development of new superplasticizers. Unfortunately, their preparation often involves multiple synthesis steps being tedious and time-consuming. ${ }^{15-17}$ Hence, branched polymer structures are needed, which can be formed in just a few reaction steps.

In light of this, hyperbranched polyglycerols represent a promising candidate as they can be obtained in one single step. ${ }^{18}$ They are synthesized by anionic ring opening multibranching polymerization (ROMP) of glycidol yielding branched polyether polyols with a globular structure and numerous hydroxyl functionalities in the inner and outer

Received: April 16, 2019

Revised: June 17, 2019

Accepted: June 22, 2019

Published: June 23, 2019 
sphere. ${ }^{19}$ Hyperbranched polyglycerols have gained much attention over the last years due to their outstanding properties. They are nontoxic and highly water-soluble and exhibit a high chemical stability and low intrinsic viscosity, and their molecular weight can be tuned over a broad range. ${ }^{18,20}$ From a chemical perspective, they are highly interesting because the hydroxyl groups in the periphery can be derivatized by various functional groups. ${ }^{21}$ Owing to their excellent biocompatibility, hyperbranched polyglycerols are widely used in biomedical and pharmaceutical applications such as in polymer therapeutics, for controlled drug release, in the fabrication of antifouling surfaces, in tissue engineering, or as imaging agent. ${ }^{20,22}$ Meanwhile, they were also applied for other purposes such as for the biomimetic crystallization of calcium carbonate ${ }^{23}$ or as an additive in aqueous printing inks to improve the color fastness. ${ }^{24}$ Hitherto, hyperbranched polyglycerols have not been considered as a structural motif for superplasticizers. Therefore, this study aims to present the synthesis of a new type of superplasticizer, which contains a hyperbranched polyglycerol scaffold, and to evaluate the dispersing properties of such moieties in cement. On the basis of previous work from Frey and co-workers, the hyperbranched polymer was synthesized from a polyether monoamine (Jeffamine) and glycidol using the slow monomer addition approach. ${ }^{25}$ Thereafter, some of the hydroxyl groups in the periphery of the polyglycerol scaffold were carboxymethylated to facilitate the adsorption of the polymer on cement. In this way, a polymer was obtained whose structure resembles a jellyfish made up from a linear polyetheramine side chain and a hyperbranched polyglycerol unit. To ascertain the steric effect of this superplasticizer, additionally, a carboxymethylated hyperbranched polyglycerol without any side chain as well as a linear non-hyperbranched molecule with two carboxylate groups were synthesized as reference compounds. The dispersing performance and slump retention ability of all synthesized polymers were investigated via mini-slump tests and compared with the results obtained for a conventional comb-shaped PCE. Isothermal heat flow calorimetry as well as adsorption and zeta potential measurements were performed to elucidate the working mechanism of the novel hyperbranched superplasticizer. The overall goal of this study was to find out whether hyperbranched polyglycerols can provoke a sufficient steric hindrance effect.

\section{MATERIALS AND METHODS}

2.1. Cement. An ordinary Portland cement CEM I $52.5 \mathrm{~N}$ ("Milke classic" from HeidelbergCement, plant Geseke, Germany) was used in the study. Its phase composition as obtained by quantitative X-ray diffraction analysis (Q-XRD) using the Rietveld method is shown in Table 1.

The amount of anhydrite $\left(\mathrm{CaSO}_{4}\right)$ and calcium sulfate hemihydrate $\left(\mathrm{CaSO}_{4} \cdot 1 / 2 \mathrm{H}_{2} \mathrm{O}\right)$ was determined by thermogravimetry, and the free lime content was assessed according to the method of Franke. The cement exhibited a $d_{50}$ value of $13.45 \mu \mathrm{m}$ (determined by laser granulometry) and a specific surface area (Blaine value) of $3479 \mathrm{~cm}^{2} / \mathrm{g}$. The density of the cement was $3.19 \mathrm{~g} / \mathrm{cm}^{3}$ (helium pycnometry).

2.2. Chemicals. Glycidol (purity $\geq 96 \%$ ) was received from Arcos Organics, and potassium methoxide (KOMe; $\geq 90 \%$ ) was from Alfa Aesar, while trimethylolpropane (TMP; $\geq 99 \%$ ), sodium chloroacetate $(\geq 98 \%)$, methyl acrylate $(\geq 99 \%)$, imidazole $(\geq 99 \%)$, phthalic anhydride $(\geq 98 \%)$, and sodium
Table 1. Phase Composition of the Cement Sample As Determined by Q-XRD

\begin{tabular}{lr}
\multicolumn{1}{c}{ phase } & wt \% \\
$\mathrm{C}_{3} \mathrm{~S}$ & 53.3 \\
$\mathrm{C}_{2} \mathrm{~S}$ & 25.7 \\
$\mathrm{C}_{3} \mathrm{~A}$ & 8.8 \\
$\mathrm{C}_{4} \mathrm{AF}$ & 2.6 \\
free lime (Franke) & 0.1 \\
anhydrite $^{a}$ & 3.3 \\
hemihydrate $^{a}$ & 0.7 \\
dihydrate $^{a}$ & 0.1 \\
calcite & 3.9 \\
quartz & 1.0 \\
arcanite & 0.5 \\
total & 100 \\
${ }^{a}$ Determined by thermogravimetry. &
\end{tabular}

hydroxide $(\geq 98 \%)$ were obtained from Merck (Darmstadt, Germany).

Jeffamine M-1000, which represents a $\omega$-methoxy terminated polyether monoamine with an average molar mass of $\sim 1000 \mathrm{~g} / \mathrm{mol}$, was provided by Huntsman (Everberg, Belgium). The Jeffamine contains ethylene (EO) and propylene oxide (PO) units at a molar ratio of 19:3.

Tetrahydrofuran (THF) and methanol were purified via vacuum distillation and stored over a molecular sieve with a pore size of $4 \AA$. Pyridine $(\geq 99 \%)$ was obtained from VWR Chemicals (Darmstadt, Germany) and used as is. The deionized (DI) water was additionally purified by a Diamond water filtration system.

For the synthesis of the reference PCE superplasticizer, sodium persulfate $(\geq 99 \%)$ from Merck and 3-mercaptopropionic acid ( $\geq 99 \%)$ from Sigma-Aldrich were utilized. The MPEG macromonomer (Polyglykol MA 2000) was supplied by Clariant (Burgkirchen, Germany).

2.3. Synthesis of the Hyperbranched Superplasticizer Jeff(hyp.PG)(COOH) $)_{n}$. The hyperbranched superplasticizer (denoted as Jeff(hyp.PG) $(\mathrm{COOH})_{n}$ ) was synthesized in a three step synthesis starting from Jeffamine M-1000 (see Scheme 1).

The synthesis was performed in flame-dried glass equipment under argon using a standard Schlenk technique. First, Jeffamine M-1000 was reacted with two equivalents of glycidol to obtain a bis-glycidolized intermediate that contains four hydroxyl groups per molecule. ${ }^{25}$ For this purpose, $30 \mathrm{~g}$ (30 $\mathrm{mmol}$ ) of Jeffamine M-1000 was added under argon into a Schlenk flask and heated to $120{ }^{\circ} \mathrm{C}$ in an oil bath. Within 30 $\mathrm{min}, 4 \mathrm{~mL}$ ( $60 \mathrm{mmol}, 4.44 \mathrm{~g}$ ) of glycidol was injected using a syringe over a septum and stirred overnight. The mixture was cooled down from $120{ }^{\circ} \mathrm{C}$ to ambient temperature to obtain the bis-glycidolized Jeffamine.

Next, $10 \%$ of the hydroxyl groups of the adduct was deprotonated by adding $1.41 \mathrm{~mL}$ ( $5.2 \mathrm{mmol}, 0.4$ equiv) of a 3.7 $\mathrm{M}$ potassium methoxide solution in methanol to $15 \mathrm{~g}$ (13.1 mmol, 1 equiv) of the bis-glycidolized Jeffamine and then stirred for $2 \mathrm{~h}$ at $70{ }^{\circ} \mathrm{C}$. Thereafter, methanol was completely removed under high vacuum, and the partially deprotonated Jeffamine based intermediate was transferred into a three necked round-bottom flask equipped with a stirrer and a Dean-Stark apparatus using $50 \mathrm{~mL}$ of anhydrous THF. The solution was heated up to $120{ }^{\circ} \mathrm{C}$, and THF was evaporated to yield a rather pure deprotonated intermediate. Next, a solution 
Scheme 1. Synthesis of the Jellyfish-Like Superplasticizer Jeff(hyp.PG)(COOH) ${ }_{n}$<smiles>COCCC(C)OCC(C)N</smiles>

Jeffamine M-1000<smiles>CC(C)OCC(C)OCC(C)N(CC(O)CO)CC(O)CO</smiles>

Bis-glycidolized Jeffamine M-1000

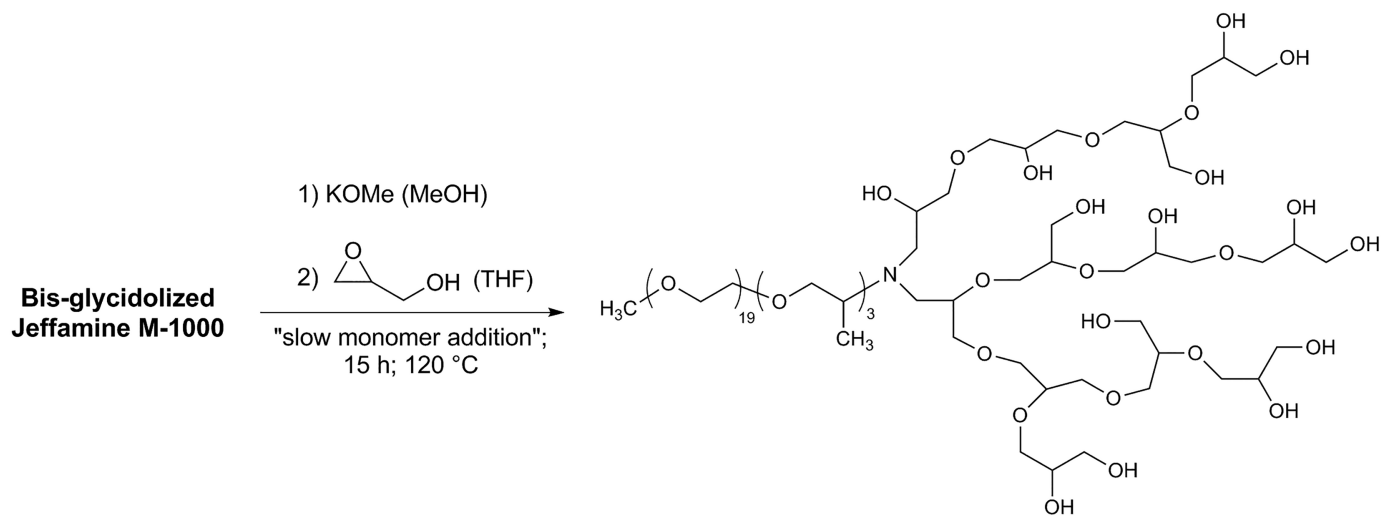

Jeff(hyp.PG)

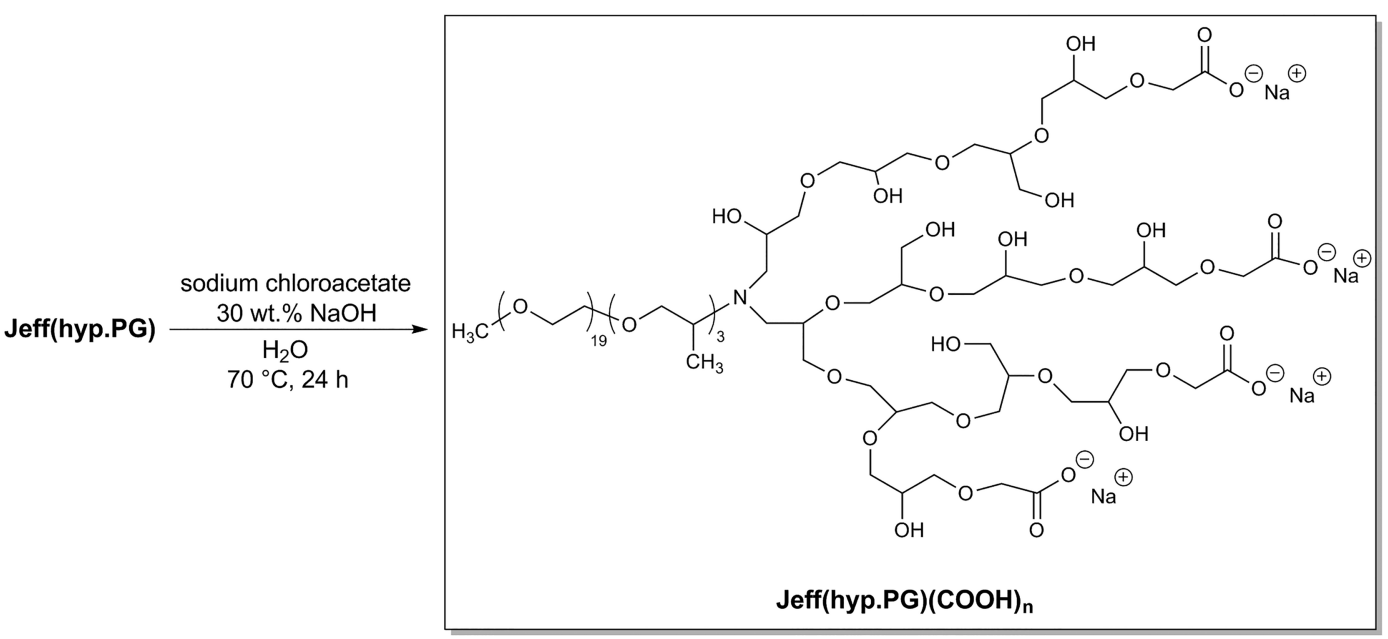

of $35 \mathrm{~mL}$ (38.9 g, $525 \mathrm{mmol}, 40$ equiv) of glycidol in $120 \mathrm{~mL}$ of THF was slowly added over $15 \mathrm{~h}$ using a peristaltic pump. After addition was complete, $60 \mathrm{~mL}$ of THF was added, and the solution was stirred for another $2 \mathrm{~h}$ at $100{ }^{\circ} \mathrm{C}$. THF was finally evaporated under reduced pressure to obtain brownish, highly viscous Jeff(hyp.PG) polymer as the intermediate.

The hydroxyl groups of the polyglycerol scaffold were then carboxymethylated as a final step. At first, $37 \mathrm{~g}$ (corr. to 373 mmol of OH groups) of Jeff(hyp.PG) was dissolved in aqueous $\mathrm{NaOH}$ solution prepared from $25.4 \mathrm{~g}$ of $\mathrm{NaOH}$ and $80 \mathrm{~mL}$ of DI water. Subsequently, a solution of $73.9 \mathrm{~g}(634 \mathrm{mmol})$ of sodium chloroacetate in $95 \mathrm{~mL}$ of DI water was added within $30 \mathrm{~min}$ at ambient and heated to $80{ }^{\circ} \mathrm{C}$ for $20 \mathrm{~h}$. The solution was cooled to ambient temperature, and the $\mathrm{pH}$ was adjusted from 11.7 to 6.0 using $37 \mathrm{wt} \% \mathrm{HCl}$. The product was purified via dialysis using dialysis membranes (Spectra/Por7 from Spectrum Laboratories) with a molecular weight cut off
(MWCO) of $1 \mathrm{kDa}$. Dialysis was performed in $2 \mathrm{~L}$ of DI water that was exchanged every $2 \mathrm{~h}$ over a period of $12 \mathrm{~h}$. The aqueous solution of the purified Jeff(hyp.PG $)(\mathrm{COOH})_{n}$ was concentrated under vacuum to a solid content of $30 \mathrm{wt} \%$. The hyperbranched superplasticizer was obtained as a yellowish, slightly viscous polymer solution with a $\mathrm{pH}$ of 5.1.

2.4. Synthesis of TMP(hyp.PG)(COOH $)_{n}$. Moreover, a carboxymethylated hyperbranched polyglycerol was synthesized that does not comprise a linear EO/PO side chain. This polymer was denoted as TMP(hyp.PG $)(\mathrm{COOH})_{n}$ and prepared in a two-step synthesis from trimethylol propane (TMP) and glycidol (see Scheme 2).

Synthesis was performed following the general procedure presented for the hyperbranched Jeff(hyp.PG) $(\mathrm{COOH})_{n}$, and a detailed description can be found in refs 19 and 23. The anionic ring opening polymerization of glycidol was initiated by the partially deprotonated (10\%) TMP and carried out in 
Scheme 2. Synthesis Route for TMP(hyp.PG $)(\mathrm{COOH})_{n}$ Starting from Trimethylol Propane

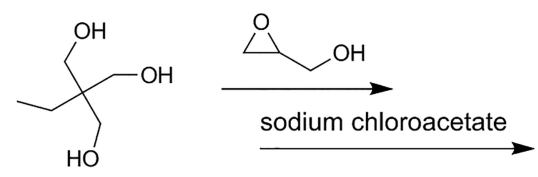

TMP

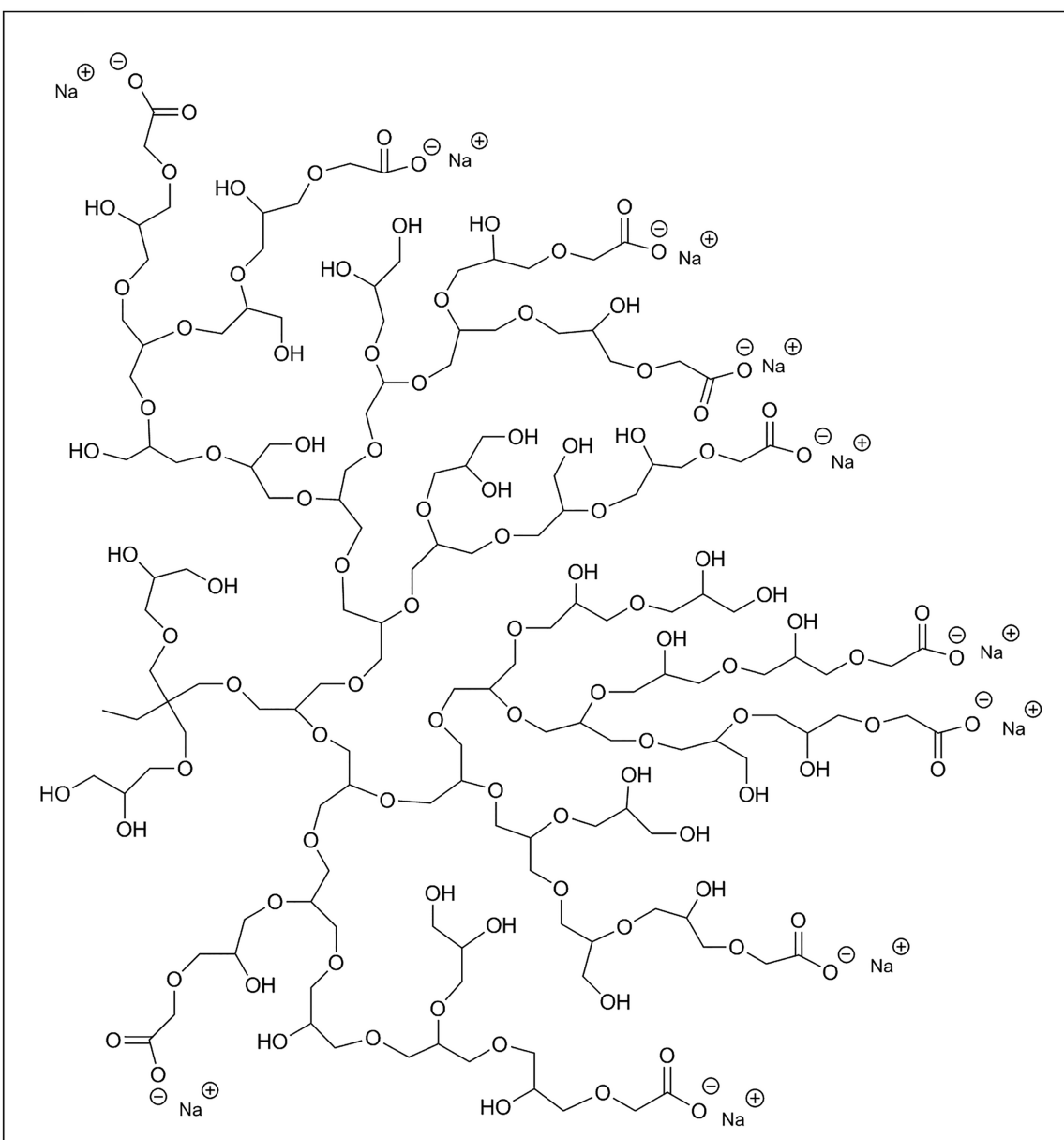

TMP(hyp.PG)(COOH)n

Scheme 3. Synthesis of the Linear, Non-hyperbranched Jeff(Et-COOH $)_{2}$

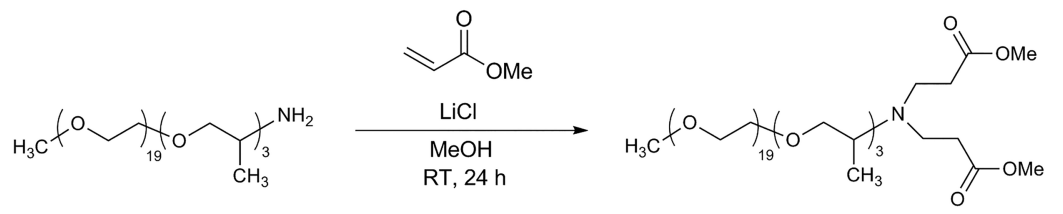

Jeffamine $M-1000$

Jeff(Et-COOMe)

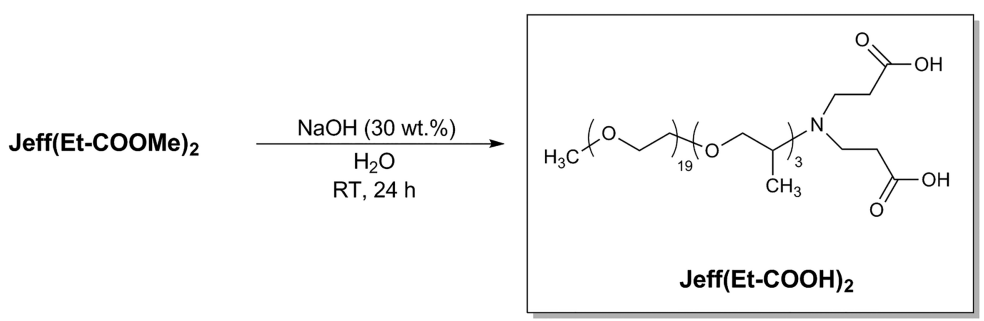

bulk. The molar ratio of glycidol to TMP was 40:1. For the carboxymethylation, $45 \mathrm{~g}$ (corr. to $641 \mathrm{mmol}$ of $\mathrm{OH}$ groups) of TMP(hyp.PG) was used, dissolved in a $\mathrm{NaOH}$ solution prepared from $43.6 \mathrm{~g}$ of $\mathrm{NaOH}$ in $125 \mathrm{~mL}$ of DI water, and then, a sodium cloroacetate solution $(127 \mathrm{~g}$ in $160 \mathrm{~g}$ of DI water, $1.09 \mathrm{~mol}$ ) was added dropwise over $2 \mathrm{~h}$ at ambient temperature. After a reaction time of $20 \mathrm{~h}$ at $80{ }^{\circ} \mathrm{C}$ and purification of the product via dialysis, TMP(hyp.PG)$(\mathrm{COOH})_{n}$ was obtained as a pale yellowish, slightly viscous solution with a solid content of 27 wt \% and a $\mathrm{pH}$ of 5.8. 
Scheme 4. Synthesis of the Comb-Shaped PCE 45 PC2

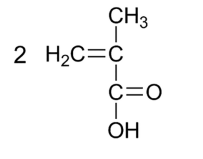

methacrylic acid

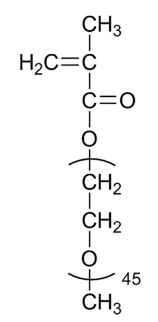

MPEG

macromonome

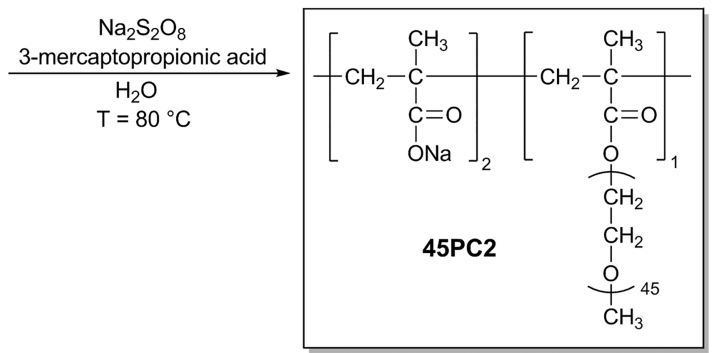

2.5. Synthesis of the linear Jeff(Et-COOH $)_{2}$. As reference, also a linear, non-hyperbranched molecule was synthesized via a Michael-type reaction of Jeffamine M-1000 and methylacrylate (see Scheme 3).

At first, $100 \mathrm{~g}$ ( $100 \mathrm{mmol}, 1$ equiv) of Jeffamine M-1000 and $300 \mathrm{mg}(7 \mathrm{mmol})$ of $\mathrm{LiCl}$ were dissolved in $80 \mathrm{~mL}$ of $\mathrm{MeOH}$ and cooled to $0{ }^{\circ} \mathrm{C}$ in an ice-water bath. Thereafter, $30.1 \mathrm{~g}$ ( $350 \mathrm{mmol}, 3.5$ equiv) of methyl acrylate was added over 10 min and stirred for 1 day at ambient. After $\mathrm{MeOH}$ was removed under reduced pressure, alkaline hydrolysis of the ester functionalities was carried out. First, the residue was dissolved in $70 \mathrm{~g}$ of DI water; then, $55 \mathrm{~g}$ of a $30 \mathrm{wt} \% \mathrm{NaOH}$ solution was added, and the aqueous solution was stirred for another day at ambient. Purification was carried out via dialysis according to the procedure presented above. Finally, the aqueous purified Jeff(Et-COOH $)_{2}$ solution was concentrated under vacuum, and a cationic exchange resin (Dowex 50WX8 hydrogen form, 200-400 mesh) was added to adjust to a slightly acidic $\mathrm{pH}$ of 6 . The solution was stirred overnight, and the exchange resin was removed by vacuum filtration. After evaporation of the solvent under reduced pressure, Jeff(Et$\mathrm{COOH})_{2}$ remained as a white, wax-like solid.

2.6. Synthesis of the Comb-Shaped PCE Superplasticizer. The comb-shaped superplasticizer was synthesized by aqueous free radical copolymerization of methacrylic acid and $\omega$-methoxypolyethylene glycol methacrylate (MPEG macromonomer comprising 45 ethylene oxide units) (see Scheme 4).

The PCE was prepared at a molar ratio of methacrylic acid to MPEG macromonomer of $2: 1$; thus, it was designated as 45PC2. Synthesis was carried out as follows: $45 \mathrm{~g}$ of DI water was added into a five necked round-bottom flask equipped with a stirrer, inlet for $\mathrm{N}_{2}$ gas, reflux condenser, and thermometer, purged with $\mathrm{N}_{2}$ for $1 \mathrm{~h}$, and subsequently heated to $80^{\circ} \mathrm{C}$. Next, two solutions were prepared. Solution I presented a mixture of $19 \mathrm{~g}(221 \mathrm{mmol}, 2$ equiv $)$ of methacrylic acid, $402 \mathrm{~g}$ (111 mmol, 1 equiv) of MPEG macromonomer ( $55 \mathrm{wt} \%$ solution) and $2.34 \mathrm{~g}$ ( $22 \mathrm{mmol}, 0.2$ equiv) of 3-mercaptopropionic acid (= chain transfer agent) in $20 \mathrm{~g}$ of DI water, while solution II consisted of $2.63 \mathrm{~g}$ (11 mmol, 0.1 equiv) of sodium persulfate (= initiator) in $80 \mathrm{~g}$ of water. Both solutions were fed continuously over $4 \mathrm{~h}$ (solution I) or $5 \mathrm{~h}$ (solution II) into the reaction vessel using two peristaltic pumps. After addition was complete, the polymer solution was stirred for one more hour at $80{ }^{\circ} \mathrm{C}$ and cooled to ambient. Finally, a pH of 7 was adjusted by using 30 wt \% $\mathrm{NaOH}$ to obtain a yellowish, slightly viscous polymer solution with a solid content of 31.9 wt \% as final product.
2.7. Characterization of the Polymers. 2.7.1. Titration According to Elder and Co-Workers. ${ }^{26}$ The number of hydroxyl groups in the polyglycerol scaffold of TMP/ Jeff(hyp.PG) was determined by the titration method established by Elder and co-workers. ${ }^{26}$ On the basis of this value, the amount of sodium chloroacetate was calculated. A detailed description of the procedure can be found in the Supporting Information.

2.7.2. NMR and FT-IR Analysis. ${ }^{1} \mathrm{H}$ and ${ }^{13} \mathrm{C}$ NMR spectra were recorded on an AVANCE-III $400 \mathrm{MHz}$ NMR spectrometer (Bruker BioSpin $\mathrm{GmBH}$, Karlsruhe, Germany). The chemical shifts were referenced to the residual nondeuterated solvent signal $\left(\mathrm{D}_{2} \mathrm{O}:{ }^{1} \mathrm{H}\right.$ NMR $\left.\delta=4.79 \mathrm{ppm}\right)$. Infrared spectra were measured on a Vertex 70 FT-IR spectrometer (Bruker) using a diamond ATR unit.

2.7.3. Size Exclusion Chromatography. The molar masses $\left(M_{\mathrm{w}}, M_{\mathrm{n}}\right)$ and the polydispersity (PDI) of the polymer samples were determined by size exclusion chromatography (SEC) using a Waters separation module equipped with a refractive index detector (2414 module from Waters, Eschborn, Germany) and a Dawn EOS 3 angle static light scattering detector (Wyatt Technology, Clinton, IA). Solutions of the polymers with a concentration of $10 \mathrm{~g} / \mathrm{L}$ were prepared using $0.1 \mathrm{M} \mathrm{NaNO}_{3}$ as solvent (adjusted with $\mathrm{NaOH}$ to $\mathrm{pH}=12$ ), which was also applied as eluent for the SEC instrument. The solutions were filtered through a $0.2 \mu \mathrm{m}$ syringe filter and separated on a precolumn and three Ultrahydrogel columns $(150,250,500)$ at a flow rate of $1.0 \mathrm{~mL} / \mathrm{min}$. For the calculation of $M_{\mathrm{w}}$ and $M_{\mathrm{n}}$, a dn/dc of $0.12 \mathrm{~mL} / \mathrm{g}$ (value for polyglycerol) was adopted, ${ }^{27}$ whereas for the comb-shaped and linear polymer, a $\mathrm{d} n / \mathrm{d} c$ of $0.135 \mathrm{~mL} / \mathrm{g}$ (value of poly(ethylene oxide)) was utilized. ${ }^{28}$

2.7.4. Anionic Charge Amount. For the quantitative determination of the anionic charge amount, a polyelectrolyte titration was conducted using a particle charge titrator (PCD $03 \mathrm{pH}$ from BTG Instruments, Herrsching, Germany). The streaming potential of the anionic polymers was captured through titration of a cationic polyelectrolyte (polyDADMAC) until charge neutralization was achieved. At first, aqueous solutions of the superplasticizer samples (conc. $0.1 \mathrm{~g} / \mathrm{L}$ ) were prepared using a synthetic cement pore solution (SCPS; $\mathrm{pH}=$ $12.8)$ and $0.1 \mathrm{M} \mathrm{NaOH}(\mathrm{pH}=13)$ as solvent. The SCPS was prepared from $1.720 \mathrm{~g}$ of $\mathrm{CaSO}_{4} \cdot 2 \mathrm{H}_{2} \mathrm{O}, 6.959 \mathrm{~g}$ of $\mathrm{Na}_{2} \mathrm{SO}_{4}$, $4.757 \mathrm{~g}$ of $\mathrm{K}_{2} \mathrm{SO}_{4}$, and $7.120 \mathrm{~g}$ of $\mathrm{KOH}$ in $1 \mathrm{~L}$ of DI water, whose ion content represents the typical composition of the pore solution of an ordinary Portland cement. For the measurement, $10 \mathrm{~mL}$ of the polymer solution was pipetted into the measuring cell of the instrument, and a $0.001 \mathrm{M}$ polydiallyldimethylammonium chloride (polyDADMAC) sol- 
ution was titrated to the sample until the isoelectric point $(=0$ $\mathrm{mV}$ ) was reached. Every sample was measured three times, and the values obtained were averaged. The anionic charge amount of the polymers was calculated from the amount of consumed polyDADMAC as described in ref 29.

2.7.5. Hydrodynamic Radius. The hydrodynamic radius $\left(R_{\mathrm{h}}\right)$ of the polymers was measured via dynamic light scattering (DLS) using a Zetasizer Nano instrument (Malvern Instruments, Worchestershire, UK). Aqueous solutions of the polymers with a concentration of $10 \mathrm{~g} / \mathrm{L}$ were prepared in SCPS and filtered through a $0.2 \mu \mathrm{m}$ syringe filter into a cuvette to remove dust particles, which could impair the measurement due to their high light scattering intensity. The cuvette was placed into the instrument and equilibrated for $120 \mathrm{~s}$ at $25{ }^{\circ} \mathrm{C}$ before the measurement was started. The hydrodynamic radius was captured five times for every sample, and the average was reported.

2.8. Test Methods. 2.8.1. Dispersing Efficacy. The dispersing performance of the polymers was ascertained via mini slump tests, which were performed according to DIN EN 1015. First, the water-to-cement ratio $(\mathrm{w} / \mathrm{c})$ of the neat cement paste for a spread flow of $18 \pm 0.5 \mathrm{~cm}$ was established. This value was used for all consecutive experiments. The mini slump tests were conducted as follows: At first, the superplasticizer was predissolved at a respective dosage $(0.1-1.2 \%$ bwoc $)$ in the mixing water contained in a porcelain cup. The water content of the superplasticizer solution was subtracted from the total amount of mixing water to perform all experiments at the same $\mathrm{w} / \mathrm{c}$ ratio. Then, $300 \mathrm{~g}$ of cement was added over $1 \mathrm{~min}$ to the mixing water, soaked for $1 \mathrm{~min}$, and subsequently agitated manually for $2 \mathrm{~min}$ with a spoon. Next, the cement slurry was transferred into a Vicat cone (height of $40 \mathrm{~mm}$, top diameter of $70 \mathrm{~mm}$, bottom diameter of $80 \mathrm{~mm}$ ) placed on a glass plate and filled to the brim. The cone was immediately lifted upward and kept for $5 \mathrm{~s}$ over the spreading cement paste. The diameter of the cement slurry was measured twice with a caliper, the first measurement being vertically to the second one, and averaged to obtain the spread flow value. The mini slump tests were carried out at a temperature of $20 \pm 1{ }^{\circ} \mathrm{C}$.

Additionally, time-dependent mini slump tests were performed to ascertain the evolution of the paste fluidity over time. For these experiments, $500 \mathrm{~g}$ of cement was used and admixed at a w/c ratio of 0.50 with the corresponding dosage of the superplasticizers for a spread flow of $26 \pm 0.5$ $\mathrm{cm}$. The cement slurry was prepared according to the procedure presented above and, after each measurement, was transferred back into the porcelain cup. The porcelain cup was covered with a wet towel to avoid any desiccation of the cement paste. Prior to each mini slump test, the cement paste was vigorously stirred for $2 \mathrm{~min}$ with a spoon. The slump (= fluidity) retaining capability of the polymers was investigated over a total period of $8 \mathrm{~h}$.

2.8.2. Adsorption Measurements. Adsorbed amounts of the polymers on cement were determined via the depletion method. Here, the amount of polymer remaining in the interstitial pore solution at the equilibrium condition after the contact with the cement was quantified by measuring the total organic carbon (TOC) content of cement pastes admixed with different dosages of the superplasticizers (i.e., $0.1-1.0 \%$ bwoc). In a typical experiment, $15 \mathrm{~g}$ of cement was added to $7.5 \mathrm{~mL}$ of DI water $(\mathrm{w} / \mathrm{c}=0.50)$ and the respective amount of polymer, placed in a centrifuge tube, homogenized for $2 \mathrm{~min}$ with a vortex mixer, and centrifuged for $10 \mathrm{~min}$ at $8500 \mathrm{rpm}$ (BioFuge, Haereus). Afterward, the supernatant was filtered through a $0.2 \mu \mathrm{m}$ syringe filter and diluted with $0.1 \mathrm{M} \mathrm{HCl}$ to avoid any carbonation of the sample. The carbon content of the supernatant was quantified using a LiquiTOC-II apparatus from Elementar Analysensysteme $\mathrm{GmbH}$ (Hanau, Germany). The measurement was repeated twice for every sample, and the obtained values were averaged and corrected by the blank TOC value found for the neat cement to consider the organic carbon content stemming, e.g., from grinding agents. The adsorbed amount of the polymer was calculated from the difference of the TOC content in the supernatant and the initial polymer solution.

2.8.3. Zeta Potential Measurements. The zeta potential of cement slurries admixed with different amounts of the superplasticizers was determined on a model DT 1200 electroacoustic spectrometer from Dispersion Technology (Bedford Hills, NY, USA). For the measurement, a cement paste was prepared at a $\mathrm{w} / \mathrm{c}$ ratio of 0.50 . Increasing dosages of the polymers $(0.01-1.0 \%$ bwoc) were added to the slurry under constant stirring in 60 incremental steps via a dosing pump.

2.8.4. Isothermal Heat Flow Calorimetry. To investigate the effect of the polymers on the hydration of cement, heat flow calorimetric measurements were carried out using a TAM Air Thermostat (TA Instruments, Järfälla, Sweden). Four grams of cement was filled into $20 \mathrm{~mL}$ glass ampules and mixed with aqueous solutions of the polymer samples to attain a $\mathrm{w} / \mathrm{c}$ ratio of 0.50 . After the addition, the glass ampules were sealed with an aluminum lid, homogenized for 2 min with a vortex mixer, and placed into the calorimeter that was precalibrated at $20{ }^{\circ} \mathrm{C}$. The heat released from cement hydration was captured until the heat evolution subsided completely.

\section{RESULTS AND DISCUSSION}

3.1. Structural Analysis of the Polymers. The hyperbranched structure of the jellyfish-like superplasticizer was achieved by anionic ring opening polymerization of glycidol using a partially deprotonated bis-glycidolized Jeffamine as initiator. Thus, a diblock copolymer was obtained, composed of one linear polyetheramine side chain and a hyperbranched polyglycerol moiety. The initiator for the ring opening polymerization was synthesized from Jeffamine and two equivalents of glycidol, yielding a bis(2,3-dihydroxypropyl) adduct with four terminal hydroxyl groups. ${ }^{25}$ This reaction was quantitative, and the formation of the product was confirmed by ${ }^{1} \mathrm{H} /{ }^{13} \mathrm{C}$ NMR spectroscopy (see Figures S6 and S7).

The key step of the synthesis comprised an anionic ring opening multibranching polymerization of glycidol. The hydroxyl groups of the bis-glycidolized Jeffamine were partially deprotonated by potassium methoxide to create nucleophilic initiating sites for the polymerization. After the addition of glycidol, the initiator attacks the unsubstituted end of the epoxide ring causing the ring to open and the formation of a secondary alkoxide and primary hydroxyl group. The fast cation exchange equilibrium between the primary and secondary alcohol group ensures that chain propagation also proceeds from the primary hydroxyl functionalities. The consecutive reaction of the terminal alkoxide groups with glycidol results in the successive formation of the polyglycerol scaffold. To synthesize hyperbranched polyglycerols with controlled molecular weight, low polydispersity, and a high 


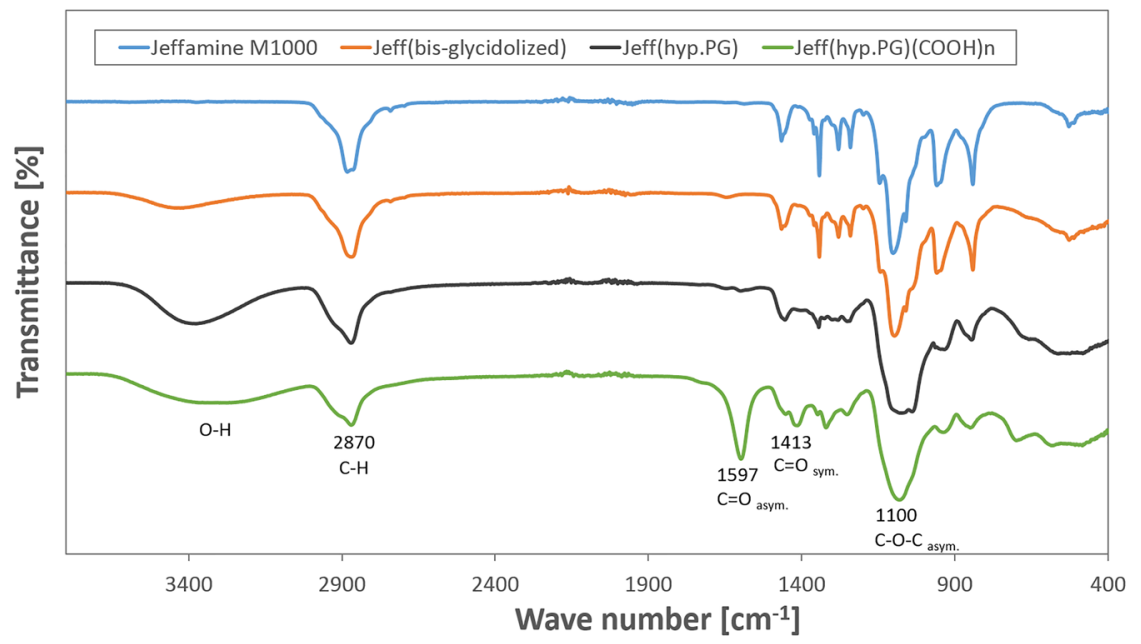

Figure 1. FT-IR spectra of Jeffamine M-1000, the intermediate products, and Jeff(hyp.PG) $(\mathrm{COOH})_{n}$.

degree of branching, the simultaneous growth of all chain ends has to be ensured. This was achieved by partial deprotonation of the initiator as well as slow monomer addition of glycidol. ${ }^{19}$ Contrary to other works in which diglyme or dixoane was used as reaction solvent, the polymerization was carried out here in bulk. ${ }^{19,25,27}$ When applying diglyme, we observed a multimodal molecular weight distribution of the polyglycerol with almost no incorporation of the Jeffamine due to solubility problems of this rather polar core unit in the aprotic solvent.

Finally, the hydroxyl groups in the periphery of the polyglycerol scaffold were carboxymethylated. This derivatization was performed under highly alkaline conditions using an excess of sodium chloroacetate ( 1.7 -fold relative to the hydroxyl groups) to ensure a high degree of substitution. Successful introduction of the carboxymethyl functionalities was evidenced by ${ }^{13} \mathrm{C}$ NMR spectroscopy via the signals for the carboxylate group at $\delta=177.7 \mathrm{ppm}$ and the carbon atom next to it at $\delta=76.9 \mathrm{ppm}$ (see Figure S12). Additionally, the FT-IR spectrum of Jeff(hyp.PG) $(\mathrm{COOH})_{n}$ showed characteristic absorption bands at 1597 and $1413 \mathrm{~cm}^{-1}$, which can be attributed to the asymmetric and symmetric $\mathrm{C}=\mathrm{O}$ stretching vibration of the carboxylate group, respectively (Figure 1).

Besides, the absorption band at $2870 \mathrm{~cm}^{-1}$ derives from the $\mathrm{C}-\mathrm{H}$ stretching vibration, and the peak at $1100 \mathrm{~cm}^{-1}$ is owed to the asymmetric stretching vibration of the ether linkages $(\mathrm{C}-\mathrm{O}-\mathrm{C})$ present in the polyetheramine side chain and the polyglycerol moiety. A comparison of the FT-IR spectra of all intermediates and the final product revealed that the intensity of the absorption band of the stretching vibration of the hydroxyl group at $\sim 3400 \mathrm{~cm}^{-1}$ increased from Jeff(bisglycidolized) to Jeff(hyp.PG) and then decreased and broadened for Jeff(hyp.PG) $(\mathrm{COOH})_{n}$, thus indicating that some of the hydroxyl groups were indeed consumed and converted into carboxymethyl functionalities.

The carboxymethylated hyperbranched polyglycerol TMP(hyp.PG) $(\mathrm{COOH})_{n}$ that exhibits an ethyl group as the "side chain" at the main branching point was synthesized from the trifunctional TMP. The results obtained from FT-IR and NMR analysis (spectra in the Supporting Information) confirmed its formation and are in compliance with data from other studies. $^{23,30}$

The non-hypyerbranched, linear molecule Jeff(Et-COOH $)_{2}$ was prepared by a Michael-type reaction of Jeffamine M-1000 and methyl acrylate using catalytic amounts of $\mathrm{LiCl}$ to enhance the electrophilic character of the carbonyl carbon atom. Carboxylate groups were then introduced by the alkaline hydrolysis of the methyl ester groups. As a result, the absorption band of the $\mathrm{C}=\mathrm{O}$ stretching vibration of the ester disappeared at $1736 \mathrm{~cm}^{-1}$ and a new band emerged in the FT-IR spectrum at $1595 \mathrm{~cm}^{-1}$, originating from the $\mathrm{C}=\mathrm{O}$ stretching vibration of the carboxylate group. The ${ }^{1} \mathrm{H} /{ }^{13} \mathrm{C}$ NMR and FT-IR spectra of the synthesized Jeff(Et-COOH $)_{2}$ are provided in the Supporting Information.

Thus, analysis confirmed that the targeted compounds Jeff(bis-glycidolized), Jeff(hyp.PG), Jeff(hyp.PG)(COOH) TMP(hyp.PG $(\mathrm{COOH})_{n}$, and Jeff(Et-COOH $)_{2}$ were successfully achieved.

3.2. Molecular Characteristics of the Polymers. Molecular properties of the synthesized polymers were ascertained by SEC. The weight and number-average molecular weights as well as the polydispersity (PDI) of the polymer samples are summarized in Table 2 .

Table 2. Molar Masses, Polydispersity (PDI), and Hydrodynamic Radii $\left(R_{h}\right)$ of the Polymers

\begin{tabular}{lrrrc}
\multicolumn{1}{c}{ polymer sample } & $\begin{array}{c}M_{\mathrm{w}} \\
{[\mathrm{g} / \mathrm{mol}]}\end{array}$ & $\begin{array}{c}M_{\mathrm{n}} \\
{[\mathrm{g} / \mathrm{mol}]}\end{array}$ & PDI & $R_{\mathrm{h}}[\mathrm{nm}]$ \\
Jeff(hyp.PG $)(\mathrm{COOH})_{n}$ & 5250 & 3790 & 1.4 & $6.7 \pm 0.2$ \\
TMP(hyp.PG $(\mathrm{COOH})_{n}$ & 6840 & 4720 & 1.4 & $5.5 \pm 0.5$ \\
Jeff(Et-COOH $)_{2}$ & 1360 & 1330 & 1.0 & $1.0 \pm 0.1$ \\
45PC2 & 39780 & 16460 & 2.4 & $6.5 \pm 0.1$ \\
\hline
\end{tabular}

The SEC spectra (Figure S1) confirm that the anionic ring opening polymerization of glycidol had indeed produced rather uniform products. Both hyperbranched polymers show an almost monodisperse molecular weight distribution indicated by a narrow polydispersity index of 1.4. In comparison, the free radical copolymerization in the PCE synthesis also produced a homogeneous product (macromonomer conversion of 93\%) but with a higher PDI of 2.4. Generally, the hyperbranched polymers exhibit relatively low molar masses compared to the comb-shaped PCE. For instance, the $M_{\mathrm{w}}$ of the jellyfish-like superplasticizer lies at $5250 \mathrm{~g} / \mathrm{mol}$, whereas for 45PC2, a value of $39780 \mathrm{~g} / \mathrm{mol}$ was found. The dynamic light scattering signal in the SEC spectrum of TMP(hyp.PG $)(\mathrm{COOH})_{n}$ revealed that the polymer contains a small fraction $(<0.1 \%)$ of a high 


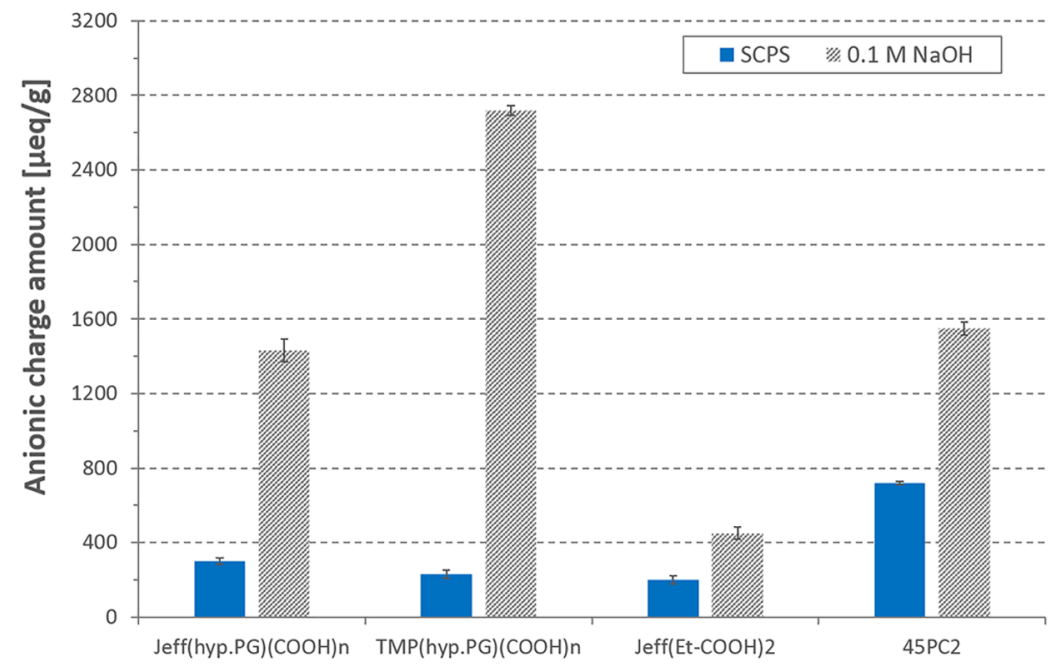

Figure 2. Anionic charge amounts of the synthesized polymers in SCPS and $0.1 \mathrm{M} \mathrm{NaOH}$.

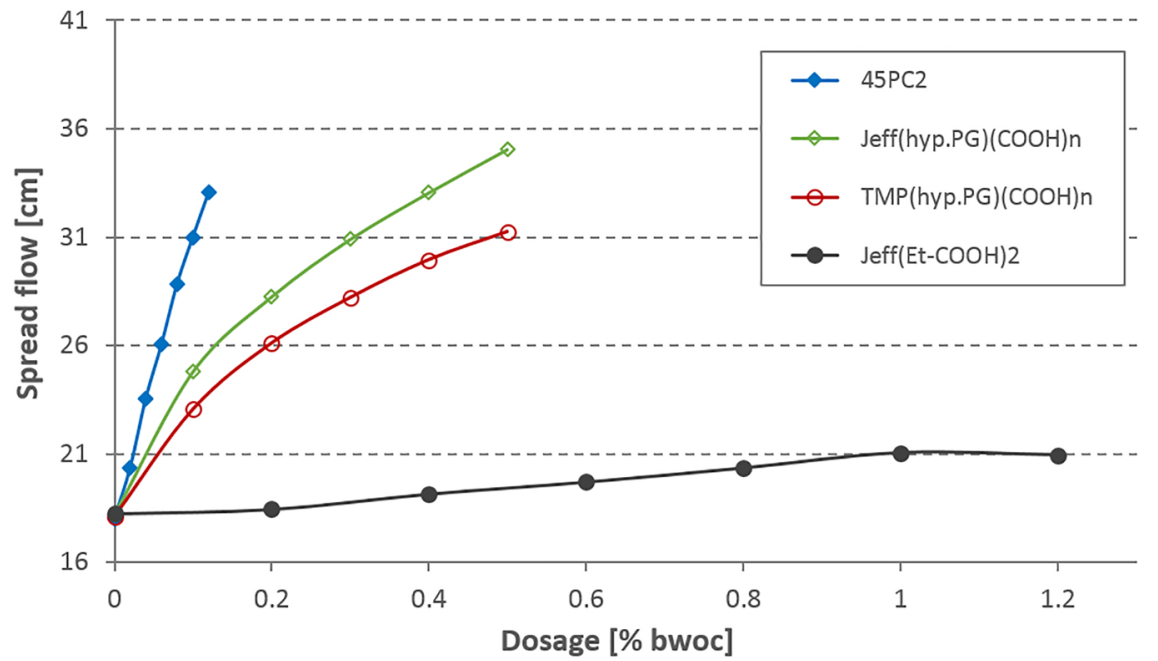

Figure 3. Dosage-dependent effect of the synthesized polymers on cement paste fluidity.

molecular weight compound, which presents a homopolymerized hyperbranched polyglycerol that was presumably formed due to the relatively high viscosity of the reaction mixture. Considering the molar masses of the polymers, it became apparent that TMP(hyp.PG $)(\mathrm{COOH})_{n}$ holds a higher proportion of the carboxymethylated hyperbranched polyglycerol skeleton than the jellyfish-like superplasticizer.

The hydrodynamic radii of the synthesized polymers are presented in Table 2. According to these results, Jeff(hyp.PG)$(\mathrm{COOH})_{n}$ exhibits a higher $R_{\mathrm{h}}$ than TMP(hyp.PG $)(\mathrm{COOH})_{n}$ and Jeff(Et-COOH $)_{2}$ as it combines the structural features of both polymers (i.e., hyperbranched polyglycerol scaffold + linear polyetheramine side chain). Surprisingly, the hydrodynamic radius of the comb-shaped PCE 45PC2 was similar to that of the jellyfish-like superplasticizer, in spite of its considerably higher molecular weight. These findings indicate that the comb-shaped PCE has a rather coiled solution conformation, whereas the hyperbranched polymers are more stretched due to the globular structure of the hyperbranched polyglycerol. Also, the propylene oxide units in the Jeffamine slightly contribute to a certain stiffness of the polyetheramine side chain.
Anionicity of the polymers was quantified via charge titration. As can be seen from Figure 2, all polymers tested showed the highest anionic charge amount in $0.1 \mathrm{M} \mathrm{NaOH}$ because there the carboxylate groups are fully deprotonated. Much lower values were obtained in SCPS, due to the complexation of $\mathrm{Ca}^{2+}$ ions by the carboxylate functionalities. The anionic charge amounts of the jellyfish-like superplasticizer and the comb-shaped PCE were comparable in $0.1 \mathrm{M} \mathrm{NaOH}$, lying at $\sim 1500 \mu \mathrm{eq} / \mathrm{g}$. However, the highest anionic charge amount was found for TMP(hyp.PG)$(\mathrm{COOH})_{n}$ (i.e., $2700 \mu \mathrm{eq} / \mathrm{g}$ in $0.1 \mathrm{M} \mathrm{NaOH}$ ), implying that there is a large number of carboxylate groups present in the hyperbranched polyglycerol skeleton. Contrary to this, the linear non-hyperbranched Jeff(Et-COOH $)_{2}$ exhibited a low anionicity because of only two carboxylate groups per molecule. Moreover, the experiments disclosed that both hyperbranched polymers have a high affinity to chelate calcium ions, since a significant decrease of the anionic charge amount was observed in SCPS.

3.3. Dispersing Performance in Cement. The dispersing efficacy of the synthesized polymers was investigated by mini slump tests. Here, different dosages of the polymers (i.e., 


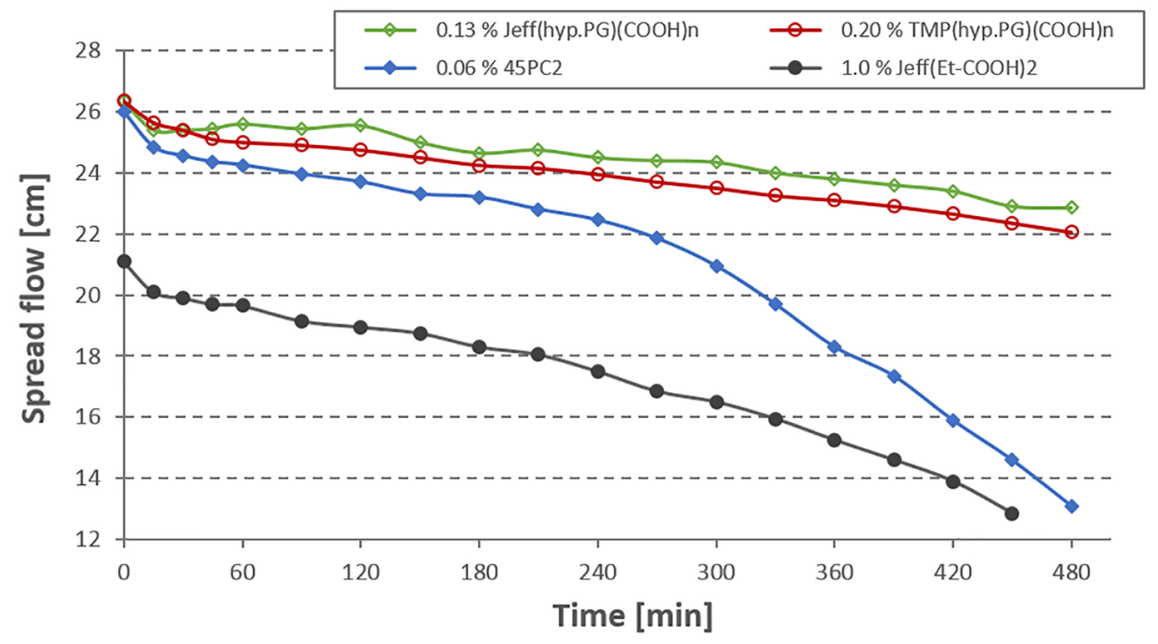

Figure 4. Time-dependent evolution of the spread flow of cement pastes admixed with the synthesized polymers $(\mathrm{w} / \mathrm{c}=0.50)$.

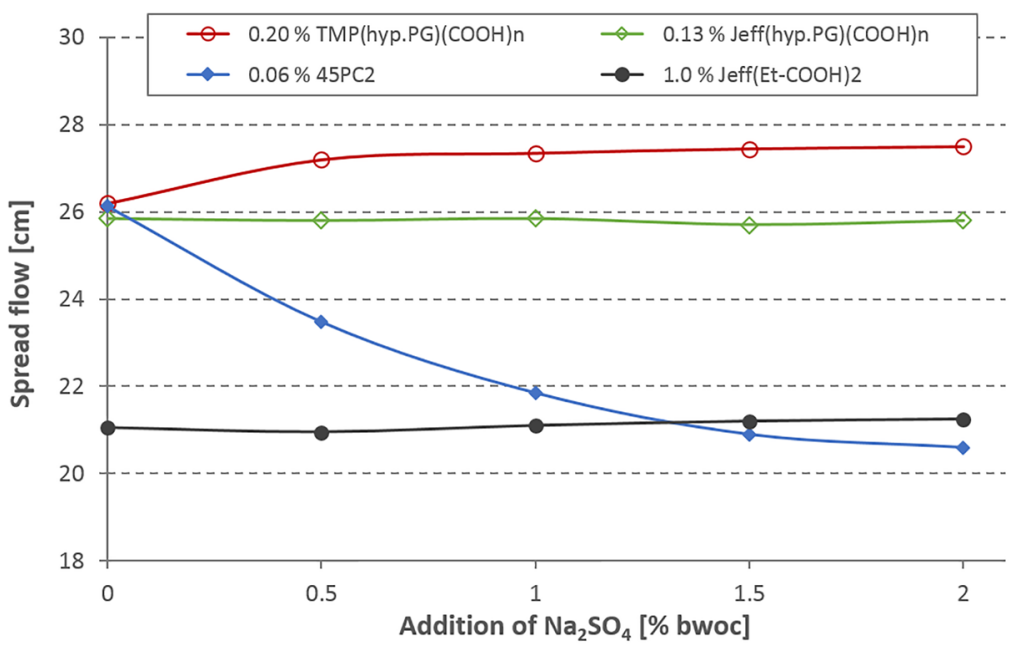

Figure 5. Impact of sodium sulfate additions on the dispersing performance of the polymers.

$0.02-1.2 \%$ by weight of cement, bwoc) were probed, and their effect on the paste fluidity was ascertained at a $\mathrm{w} / \mathrm{c}$ ratio of 0.50 (Figure 3 ). In this way, it was hoped to achieve a better understanding of the relationship between the topological structure of the polymers and their dispersing performance. As is evident from Figure 3, the dispersing ability of the linear, non-hyperbranched molecule Jeff(Et-COOH $)_{2}$ was rather limited. High dosages were necessary to achieve at least a slight increase of the fluidity (e.g., from 18 to $21 \mathrm{~cm}$ at $1.0 \%$ ). Clearly, the hyperbranched polymers were superior over the linear, non-hyperbranched Jeff(Et-COOH $)_{2}$. For instance, a dosage of only $0.20 \%$ was required for TMP(hyp.PG)$(\mathrm{COOH})_{n}$ to achieve a spread flow of $26 \mathrm{~cm}$, while Jeff(hyp.PG $)(\mathrm{COOH})_{n}$ attained this value already at $0.13 \%$. The higher efficiency of the jellyfish-like superplasticizer can be attributed to the additional steric effect imparted by the linear polyetheramine side chain (see also the higher $R_{\mathrm{h}}$ value in Table 2). The comb-shaped PCE was even more effective and required only $0.06 \%$ dosage to achieve a $26 \mathrm{~cm}$ spread flow. The higher dispersing efficacy of this polymer can be attributed to its significantly higher side chain density and thus its enhanced steric hindrance effect, compared to the jellyfish dispersant.
3.4. Slump Retention Capability. In the following, the time-dependent fluidity retention of the polymers, which presents an important aspect in actual application, was tested. For this purpose, cement pastes were fluidized with the respective dosages of the polymers to achieve a spread flow of $26 \mathrm{~cm}$, and the evolution of paste fluidity was measured over time.

According to Figure 4, the linear, non-hyperbranched Jeff(Et-COOH $)_{2}$ showed a very poor slump retention ability even at a dosage as high as $1.0 \%$. Opposite to this, Jeff(hyp.PG $)(\mathrm{COOH})_{n}$ maintained the initial fluidity over two hours before paste fluidity declined very slowly. Most remarkably, even six hours after the preparation, the cement slurry still exhibited a spread flow of $23.8 \mathrm{~cm}$. A similar behavior was observed for the other hyperbranched polymer TMP(hyp.PG) $(\mathrm{COOH})_{n}$. However, fluidity of the cement paste admixed with 45PC2, which represents a PCE which is designed to provide particularly long fluidity retention, already within the first $4 \mathrm{~h}$ decreased from 26 to $22.5 \mathrm{~cm}$ and then declined rapidly, while the hyperbranched polymers still were able to maintain high cement fluidity.

3.5. Dispersing Performance in the Presence of Sulfate. It has been established that the dispersing performance of PCEs often is much lower in cement samples with a 


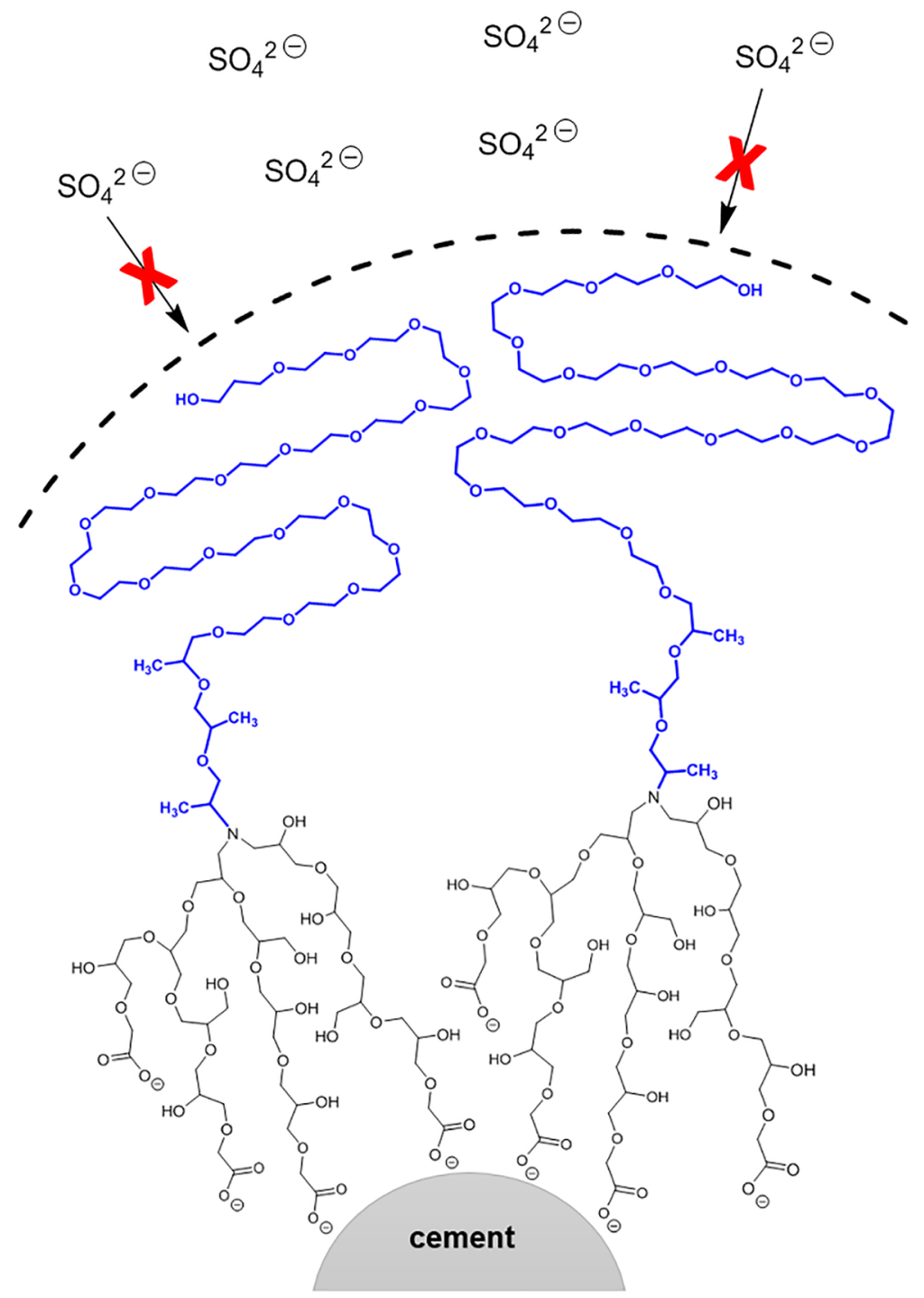

Figure 6. Schematic representation of the tail-like adsorption mode of Jeff(hyp.PG)(COOH $)_{n}$ and the hindered access of sulfate ions to the surface of the cement.

high content of immediately soluble sulfates (e.g., $\alpha$-, $\beta$ hemihydrate, alkali sulfates). ${ }^{31}$ It was found that this behavior primarily derives from competitive adsorption between the PCEs and the sulfate ions for adsorption sites. ${ }^{32}$ Therefore, in recent years, several attempts were made to develop superplasticizers that exhibit higher robustness in the presence of sulfates. $^{33,34}$ To investigate the sulfate tolerance of the polymers synthesized here, different amounts of sodium sulfate (i.e., $0.5-2.0 \%$ bwoc) were dissolved in the mixing water together with the polymers and mini slump tests were carried out $(\mathrm{w} / \mathrm{c}=0.50)$.

According to Figure 5, the dispersing performances of the hyperbranched polymers as well as of the linear, nonhyperbranched Jeff(Et-COOH $)_{2}$ are not impaired by sulfate ions. Contrary, the comb-shaped PCE 45PC2 showed a remarkably low sulfate tolerance (e.g., decrease of the spread flow from 26 to $20.6 \mathrm{~cm}$ at $\mathrm{Na}_{2} \mathrm{SO}_{4}$ addition of $2 \%$ ). The high robustness of the hyperbranched polymers and of Jeff(Et$\mathrm{COOH})_{2}$ can be attributed to their specific molecular architecture. Since all these polymers exhibit terminal carboxylate groups, they presumably adsorb in a tail (= brush)-like conformation. This means that they anchor via their chain end on the cement surface, while the rest of the structure stretches out into the pore solution. In this way, a more dense surface coverage is obtained, and a barrier for the access of hydrated sulfate ions forms, which prevents the desorption of the adsorbed polymers from the cement surface (see the illustration in Figure 6).

A similar mechanism was reported earlier for linear polyoxyethylene diphosphonate dispersants that also adsorb via their phosphonate groups in a tail-like conformation and exhibit high robustness toward soluble sulfates. ${ }^{35}$ However, the comb-shaped structure of the PCE from our study apparently favors a loop-shaped conformation, whereby only some segments of the polymer chain are attached to the cement surface. As a result of this adsorption mode, the surface is not so densely covered by the polymer and is more accessible to sulfate ions. Interestingly, the highest sulfate robustness was found for TMP(hyp.PG) $(\mathrm{COOH})_{n}$ even though it does not comprise a linear polyether side chain. This can be attributed to its high anionicity (i.e., $2700 \mu \mathrm{eq} / \mathrm{g}$ in $0.1 \mathrm{M} \mathrm{NaOH}$ ), which provokes a strong anchoring on the cement surface, thus impeding the desorption of the polymer by soluble sulfates. 


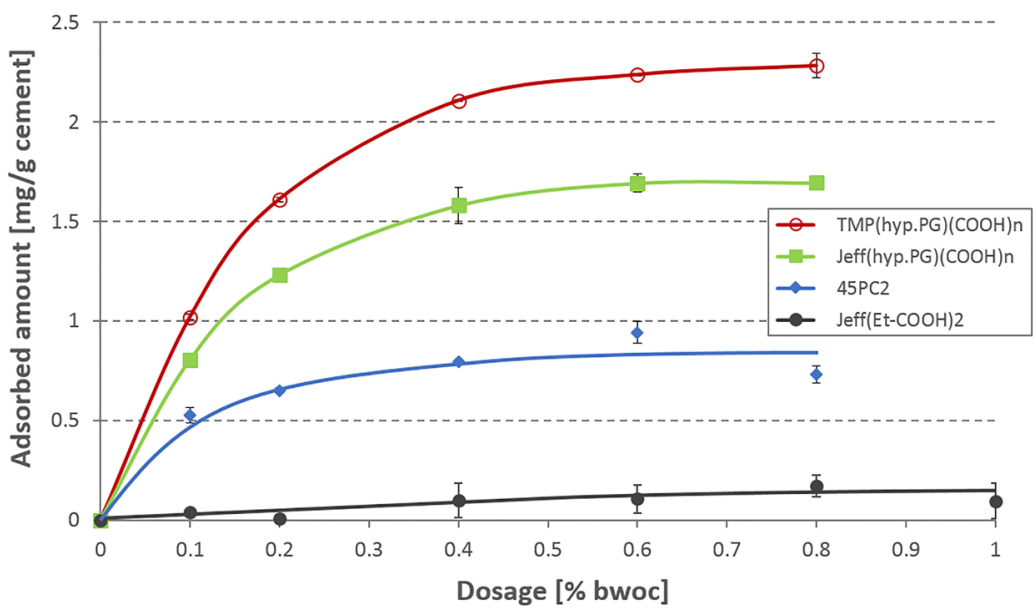

Figure 7. Adsorption isotherms on cement developed for the individual polymers at $\mathrm{w} / \mathrm{c}=0.50$.

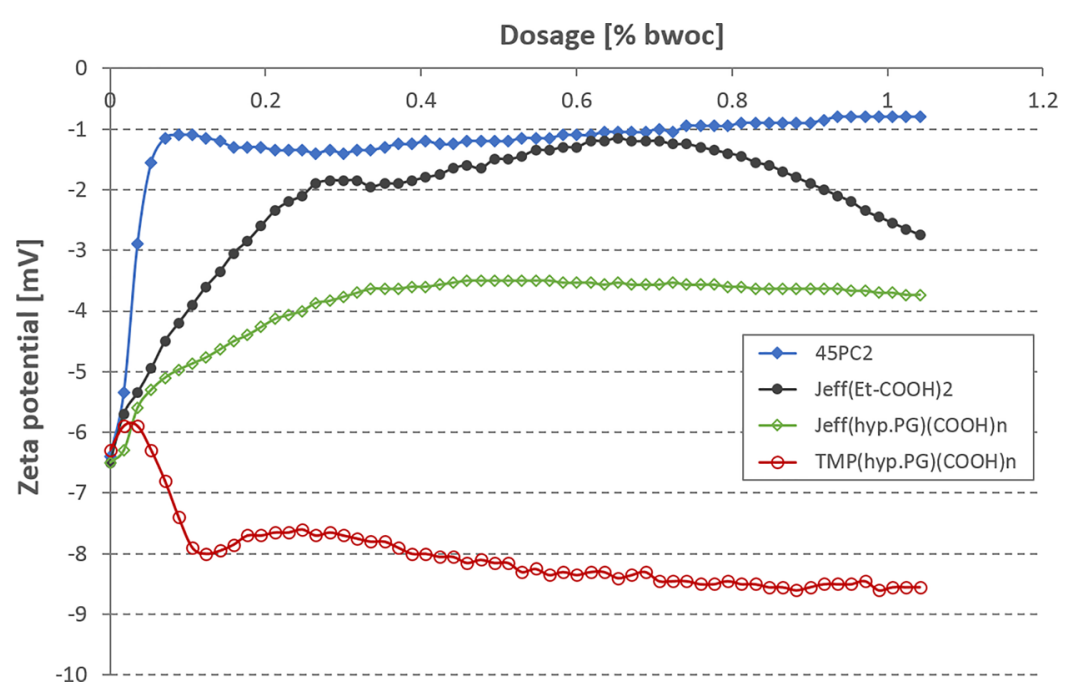

Figure 8. Zeta potential of cement slurries $(\mathrm{w} / \mathrm{c}=0.50)$ admixed with increasing polymer dosages.

3.6. Adsorption Measurements. To gain information about the adsorption of the polymers on cement, individual adsorption isotherms were developed at a $\mathrm{w} / \mathrm{c}$ ratio of 0.50 . As can be seen from Figure 7, all polymers except for Jeff(Et$\mathrm{COOH})_{2}$ showed a Langmuir-type adsorption isotherm characterized by a steep increase of the adsorbed amount at low dosages until it gradually levels off at the saturation point where all surface sites are completely covered by a monolayer of the polymer.

Generally, significantly higher adsorbed amounts were found for the hyperbranched polymers compared to the PCE. To be more specific, Jeff(hyp.PG)(COOH ${ }_{n}$ and TMP(hyp.PG)$(\mathrm{COOH})_{n}$ reached the saturated adsorption at 1.7 and $2.3 \mathrm{mg} /$ g cement, respectively, while $45 \mathrm{PC} 2$ attained the plateau at $0.84 \mathrm{mg} / \mathrm{g}$ cement only. These findings suggest that the hyperbranched polymers indeed adsorb in a tail-like conformation, which allows a more dense packing of the polymer and a higher loading of the surface. This result further supports the previous observation of a higher sulfate tolerance for these polymers. In comparison, the comb-shaped PCE occupies a much higher surface area per molecule, with its main chain spread out on the surface (loop-shaped conformation) and therefore achieves saturated adsorption already at low addition. This was confirmed by converting the adsorbed amounts in $\mathrm{mg} / \mathrm{g}$ cement into carboxylate groups $\left(\mathrm{COO}^{-}\right)$available for adsorption per $\mathrm{m}^{2}$ and plotting it against the applied polymer dosage (see Figure S19). From there, it can be seen that for the comb-shaped PCE only $2.6 \mu \mathrm{mol}$ of $\mathrm{COO}^{-}$is anchored per $\mathrm{m}^{2}$ at saturated adsorption, while significantly higher values were obtained for Jeff(hpy.PG)(COOH) ${ }_{n}$ and TMP(hyp.PG)$(\mathrm{COOH})_{n}\left(11.6\right.$ and $22 \mu \mathrm{mol} / \mathrm{m}^{2}$, respectively). For the linear non-hyperbranched Jeff(Et-COOH $)_{2}$, only low adsorbed amounts were found (e.g., $0.1 \mathrm{mg} / \mathrm{g}$ cement and $0.12 \mu \mathrm{mol} / \mathrm{m}^{2}$ at $1.0 \%$, respectively), which provide only partial surface coverage. This is the reason for the poor dispersing performance of this molecule.

3.7. Impact of the Polymers on Zeta Potential. The interaction of the polymers with cement was investigated by zeta potential measurements. Here, cement slurries $(\mathrm{w} / \mathrm{c}=$ 0.50) were admixed with increasing dosages of the polymers, and the zeta potential of the cement particles was captured using the electroacoustic method.

As is obvious from Figure 8, the polymers, which comprise linear polyether side chains, showed an increase of the zeta potential at ascending dosages until they reached a plateau. It is well established for PCE superplasticizers that this increase stems from the steric effect of the polyether side chains, which shift the shear plane of the zeta potential toward the isoelectric 


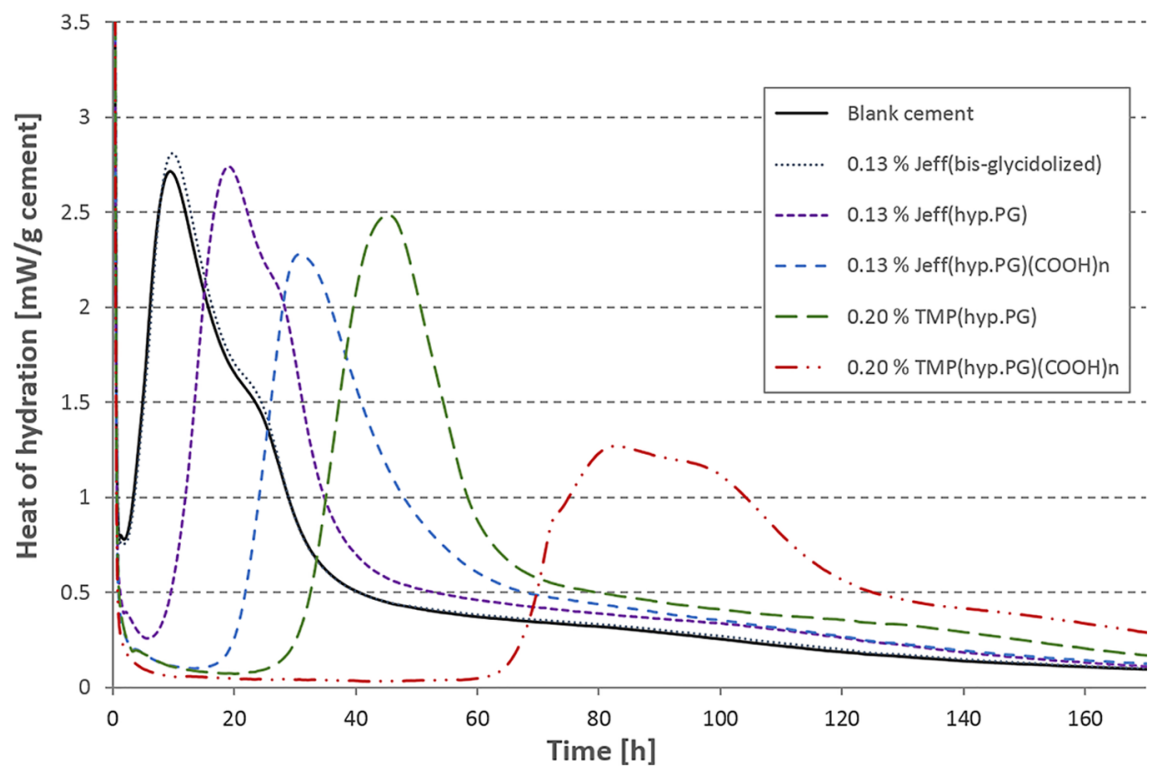

Figure 9. Time-dependent evolution of the hydration heat released from cement slurries $(\mathrm{w} / \mathrm{c}=0.50)$ admixed with different polymers.

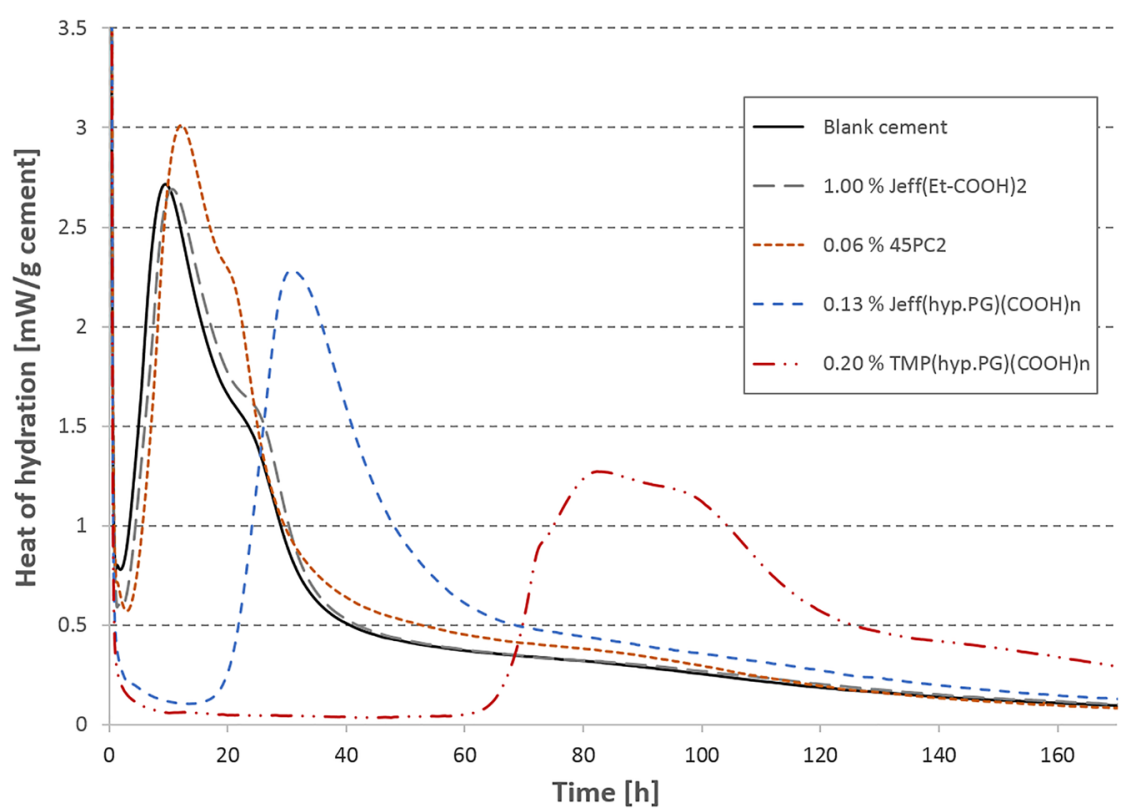

Figure 10. Time-dependent evolution of the hydration heat released from cement slurries $(\mathrm{w} / \mathrm{c}=0.50)$ admixed with different intermediates from the polymer syntheses.

point. $^{36}$ Since $45 \mathrm{PC} 2$ possesses a longer side chain than Jeff(hyp.PG) $(\mathrm{COOH})_{n}$ (45 EO units vs $19 \mathrm{EO}+3 \mathrm{PO}$ units), more positive zeta potential values were obtained for the comb-shaped PCE. Furthermore, it can be seen from the figure that 45PC2 approached the plateau level at a much lower dosage than Jeff(hyp.PG)(COOH$)_{n}$, while for Jeff(Et$\mathrm{COOH})_{2}$, no plateau value was found at all. However, TMP(hyp.PG $)(\mathrm{COOH})_{n}$ slightly decreased the zeta potential from -6.2 to $-8.8 \mathrm{mV}$, signifying that the individual hyperbranched polyglycerol scaffold imparts a lower steric hindrance effect compared to 45PC2 or Jeff(hyp.PG)$(\mathrm{COOH})_{n}$. On the basis of the zeta potential measurements, it also can be concluded that all synthesized polymers interact with the cement surface via physisorption.
3.8. Heat Flow Calorimetry. Finally, the impact of the synthesized polymers on cement hydration was investigated via isothermal heat flow calorimetry. The time-dependent heat release from cement pastes $(\mathrm{w} / \mathrm{c}=0.5)$ admixed with the respective dosages of the polymers required for a spread flow of $26 \mathrm{~cm}$ is illustrated in Figure 9.

According to this, the linear non-hyperbranched Jeff(Et$\mathrm{COOH})_{2}$ and the comb-shaped PCE delay the main peak of cement hydration only slightly compared to the blank cement (e.g., $3 \mathrm{~h}$ for 45PC2). For both hyperbranched polymers, a much stronger retardation was found. The addition of $0.13 \%$ Jeff(hyp.PG $)(\mathrm{COOH})_{n}$ resulted in a retardation of $21 \mathrm{~h}$, while $0.20 \%$ TMP(hyp.PG $)(\mathrm{COOH})_{n}$ delayed the cement hydration even for $78 \mathrm{~h}$, which explains the exceptional fluidity retention of the cement pastes containing these polymers (see Figure 4). 
To further elucidate the retarding properties of the polymers, heat flow calorimetry was also conducted for the intermediate products occurring in the syntheses.

Figure 10 confirms that the bis-glycidolized Jeffamine does not affect the cement hydration, whereas for Jeff(hyp.PG) and TMP(hyp.PG), strong retardation was evidenced (e.g., $36 \mathrm{~h}$ for TMP(hyp.PG)). However, their retarding effect was less severe than for the carboxymethylated products. These findings suggest that the retardation of the hyperbranched polymers stems not only from the carboxylate groups but also from the hyperbranched polyglycerol skeleton. Generally, retardation can be ascribed to different mechanisms: ${ }^{37}$ (a) adsorption of the polymer on the surface of cement, which reduces the access of water to facilitate hydration; (b) adsorption on initial hydration products, which blocks their further growth; (c) complexation of $\mathrm{Ca}^{2+}$ ions by the polymer and consequently reduced formation of the hydrate phases; (d) precipitation of the polymer, which acts as a diffusion barrier on the cement surface. The retarding effect of the hyperbranched polymers can be explained as follows: Through adsorption of the polymers on cement and the initial hydration products, a densely packed polymer layer is formed. As a result, the dissolution of the clinker phases and the ion transport at the solid-liquid interface as well as the growth of the initial hydrate phases are inhibited. Moreover, Jeff(hyp.PG)$(\mathrm{COOH})_{n}$ and TMP(hyp.PG $)(\mathrm{COOH})_{n}$ exhibit a high ability to complex $\mathrm{Ca}^{2+}$ ions, as was evidenced by the charge titration experiments in Section 3.2 (see Figure 2), whereas precipitation of the polymer by $\mathrm{Ca}^{2+}$ can be excluded since no precipitate was observed in SCPS.

\section{CONCLUSION}

In this study, a new type of superplasticizer was successfully synthesized by anionic ring opening multibranching polymerization of glycidol. Contrary to conventional PCEs, this polymer exhibits a linear hyperbranched diblock structure composed of a carboxmethylated hyperbranched polyglycerol moiety and one linear polyetheramine side chain at the branching point.

The terminal carboxylate groups present in the periphery of the hyperbranched polyglycerol skeleton effectuate a perpendicular (tail-like) adsorption mode, which entails higher polymer dosages required for the complete surface coverage of cement compared to conventional comb-shaped PCEs. Moreover, our study about the structure-performance relationship of the different synthesized polymers signifies that superplasticizers need at least one component that can provide a powerful steric hindrance effect and additionally must exhibit a sufficient anionic charge amount to facilitate the adsorption on cement.

The results from the time-dependent fluidity tests show that carboxymethylated hyperbranched polyglycerols provoke a superior slump loss behavior and therefore behave more favorably in applications such as ready-mix concrete where a fluid consistency has to be retained over a longer period of time until delivery at the construction site has been achieved. Considering the retarding effect of the hyperbranched superplasticizer, we suggest that such polymers might be very beneficial, e.g., for concreting at high temperatures $\left(>30{ }^{\circ} \mathrm{C}\right)$ where strong retardation actually is required or in oil well cementing where cement slurries are pumped over long distances at temperatures as high as $200{ }^{\circ} \mathrm{C}$. Future research should focus on novel hybrid structures by incorporating hyperbranched polyglycerols as side chains into comb-shaped PCEs and studying whether such branched lateral chains are more effective than the linear ones present in conventional PCEs.

\section{ASSOCIATED CONTENT}

\section{S Supporting Information}

The Supporting Information is available free of charge on the ACS Publications website at DOI: 10.1021/acs.iecr.9b02077.

Titration according to Elder and co-workers, ${ }^{26}$ SEC spectra, FT-IR spectra, ${ }^{1} \mathrm{H}$ and ${ }^{13} \mathrm{C}$ NMR data, and the adsorption measurement (PDF)

\section{AUTHOR INFORMATION}

\section{Corresponding Author}

*E-mail: sekretariat@bauchemie.ch.tum.de.

ORCID

Johann Plank: 0000-0002-4129-4784

Notes

The authors declare no competing financial interest.

\section{ACKNOWLEDGMENTS}

The authors would like to thank Huntsman for generously providing the Jeffamine sample and HeidelbergCement for supplying the cement.

\section{REFERENCES}

(1) Spiratos, N.; Page, M.; Mailvaganam, N. P.; Malhotra, V. M.; Jolicoeur, C. Superplasticizers for Concrete: Fundamentals, Technology, and Practice; Supplementary Cementing Materials for Sustainable Development: Ottawa, 2003.

(2) Plank, J.; Sakai, E.; Miao, C. W.; Yu, C.; Hong, J. X. Chemical admixtures - Chemistry, applications and their impact on concrete microstructure and durability. Cem. Concr. Res. 2015, 78, 81-99.

(3) Äitcin, P.-C.; Flatt, R. J. Science and Technology of Concrete Admixtures, 1st ed.; Woodhead Publishing, 2016.

(4) Yamada, K.; Takahashi, T.; Hanehara, S.; Matsuhisa, M. Effects of the chemical structure on the properties of polycarboxylate-type superplasticizer. Cem. Concr. Res. 2000, 30, 197-207.

(5) Zhang, Y.; Kong, X. Correlations of the dispersing capability of NSF and PCE types of superplasticizer and their impacts on cement hydration with the adsorption in fresh cement pastes. Cem. Concr. Res. 2015, 69, 1-9.

(6) Uchikawa, H.; Hanehara, S.; Sawaki, D. The role of steric repulsive force in the dispersion of cement particles in fresh paste prepared with organic admixture. Cem. Concr. Res. 1997, 27, 37-50.

(7) Jolicoeur, C.; Simard, M.-A. Chemical admixture-cement interactions: Phenomenology and physico-chemical concepts. Cem. Concr. Compos. 1998, 20, 87-101.

(8) Yoshioka, K.; Sakai, E.; Daimon, M.; Kitahara, A. Role of steric hindrance in the performance of superplasticizers for concrete. J. Am. Ceram. Soc. 1997, 80 (10), 2667-2671.

(9) Houst, Y. F.; Bowen, P.; Perche, F.; Kauppi, A.; Borget, P.; Galmiche, L.; Le Meins, J. F.; Lafuma, F.; Flatt, R. J.; Schober, I.; Banfill, P. F.G.; Swift, D. S.; Myrvold, B. O.; Petersen, B. G.; Reknes, $\mathrm{K}$. Design and function of novel superplasticizers for more durable high performance concrete (superplast project). Cem. Concr. Res. 2008, 38, 1197-1209.

(10) Hirata, T.; Ye, J.; Branicio, P.; Zheng, J.; Lange, A.; Plank, J.; Sullivan, M. Adsorbed conformations of PCE superplasticizers in cement pore solution unraveled by molecular dynamics simulations. Sci. Rep. 2017, 7, 16599.

(11) Ottewill, R. H.; Walker, T. The influence of non-ionic surface active agents on the stability of polystyrene latex dispersions. Colloid Polym. Sci. 1968, 227 (1-2), 108-116. 
(12) Liu, X.; Guan, J.; Lai, G.; Wang, Z.; Zhu, J.; Cui, S.; Lan, M.; Li, $\mathrm{H}$. Performances and working mechanism of a novel polycarboxylate superplasticizer synthesized through changing molecular topological structure. J. Colloid Interface Sci. 2017, 504, 12-24.

(13) Ao, L.; Zhao, W.; Lei, Q.; Wang, D.; Guan, Y.; Liu, K.; Guo, T.; Fan, X.; Wei, X. Synthesis of a novel polycarboxylate superplasticizer with hyperbranched structure. Chemistry Select 2018, 3, 1349313496.

(14) Zhu, Q.-H.; Zhang, L.-Z.; Min, X.-M.; Yu, Y.-X.; Zhao, X.-F.; Li, J.-H. Comb-typed polycarboxylate superplasticizer equipped with hyperbranched polyamide teeth. Colloids Surf., A 2018, 553, 272-277.

(15) Kong, X.; Hou, S.; Lu, Z. Effect of dendrimeric polyamide on fluidity of cement paste, cement hydration and their adsorption in cement paste. J. Chin. Ceram. Soc. 2014, 42 (11), 1355-1361.

(16) Shou, C.; Xiao, W. Hyper-branched polycarboxylate highefficiency water reducing agent and preparation method thereof. China Patent CN 101580353 B, 2012.

(17) Li, S.; Wu, Q.; Wang, X.; Kong, C.; Zhu, H.; Zhang, C.; Yang, T.; Wang, C.; Xu, F.; Liu, Y.; Fan, S. Hyperbranched polycarboxylate water reducer and preparation method thereof. China Patent $\mathrm{CN}$ 107325296 A, 2017.

(18) Gheybi, H.; Sattari, S.; Bodaghi, A.; Soleimani, K.; Dadkhah, A.; Adeli, M. Polyglycerols. In Engineering of Biomaterials for Drug Delivery Systems: Beyond Polyethylene Glycol; Woodhead Publishing Series in Biomaterials, 2018; pp 103-171.

(19) Sunder, A.; Hanselmann, R.; Frey, H.; Mülhaupt, R. Controlled synthesis of hyperbranched polyglycerols by ring-opening multibranching polymerization. Macromolecules 1999, 32, 4240-4246.

(20) Abbina, S.; Vappala, S.; Kumar, P.; Siren, E. M. J.; La, C. C.; Abbasi, U.; Brooks, D. E.; Kizhakkedathu, J. N. Hyperbranched polyglycerols: recent advances in synthesis, biocompatibility and biomedical applications. J. Mater. Chem. B 2017, 5, 9249-9277.

(21) Frey, H.; Haag, R. Dendritic polyglycerol: a new versatile biocompatible material. Rev. Mol. Biotechnol. 2002, 90, 257-267.

(22) Wilms, D.; Stiriba, S.-E.; Frey, H. Hyperbranched Polyglycerols: From the Controlled Synthesis of Biocompatible Polyols to Multipurpose Applications. Acc. Chem. Res. 2010, 43 (1), 129-141.

(23) Wang, G.; Li, L.; Lan, J.; Chen, L.; You, J. Biomimetic crystallization of calcium carbonate spherules controlled by hyperbranched polyglycerols. J. Mater. Chem. 2008, 18, 2789-2797.

(24) Zolek-Tryznowska, Z.; Tryznowski, M.; Krolikowska, J. Hyperbranched polyglycerol as an additive for water-based printing ink. J. Coat. Technol. Res. 2015, 12 (2), 385-392.

(25) Istratov, V.; Kautz, H.; Kim, Y.-K.; Schubert, R.; Frey, H. Linear-dendritic nonionic poly(propylene oxide)-polyglycerol surfactants. Tetrahedron 2003, 59, 4017-4024.

(26) Carey, M. A.; Wellons, S. L.; Elder, D. K. Rapid method for measuring the hydroxyl content of polyurethane polyols. J. Cell. Plast. 1984, 20, 42-48.

(27) Kainthan, R. K.; Muliawan, E. B.; Hatzikiriakos, S. G.; Brooks, D. E. Synthesis, characterization, and viscoelastic properties of high molecular weight hyperbranched polyglycerols. Macromolecules 2006, 39, 7708-7717.

(28) Kawaguchi, S.; Aikaike, K.; Zhang, Z.-M.; Matsumoto, K.; Ito, K. Watersoluble bottlebrushes. Polym. J. 1998, 30, 1004-1007.

(29) Plank, J.; Sachsenhauser, B. Experimental determination of the effective anionic charge density of polycarboxylate superplasticizers in cement pore solution. Cem. Concr. Res. 2009, 39, 1-5.

(30) Barriau, E.; Frey, H.; Kiry, A.; Stamm, M.; Gröhn, F. Negatively charged hyperbranched polyether-based polyelectrolytes. Colloid Polym. Sci. 2006, 284, 1293-1301.

(31) Magarotto, R.; Moratti, F.; Zeminian, N. Influence of sulfates content in cement on the performance of superplasticizers. In Proceedings of the 8th CANMET/ACI Conference on Superplasticizers and Other Chemical Admixtures in Concrete; Malhotra, V. M., Ed., Sorrento, Italy, 2006; SP-239-15; pp 215-229.

(32) Han, S.; Plank, J. Mechanistic study on the effect of sulfate ions on polycarboxylate superplasticizers in cement. Adv. Cem. Res. 2013, 25 (4), 200-207.
(33) Pourchet, S.; Liautaud, S.; Rinaldi, D.; Pochard, I. Effect of the repartition of the PEG side chains on the adsorption and dispersion behaviors of PCP in presence of sulfate. Cem. Concr. Res. 2012, 42, 431-439.

(34) Habbaba, A.; Lange, A.; Plank, J. Synthesis and performance of a modified polycarboxylate dispersant for concrete possessing enhanced cement compatibility. J. Appl. Polym. Sci. 2013, 129, $346-353$.

(35) Mosquet, M.; Chevalier, Y.; Brunel, S.; Guicquero, J. P.; Le Perchec, P. Polyoxyethylene di-phosphonates as efficient dispersing polymers for aqueous suspensions. J. Appl. Polym. Sci. 1997, 65, 2545-2555.

(36) Plank, J.; Sachsenhauser, B. Impact of molecular structure on zeta potential and adsorbed conformation of $\alpha$-allyl- $\omega$-methoxypolyethylene glycol-maleic anhydride superplasticizers. J. Adv. Concr. Technol. 2006, 4 (2), 233-239.

(37) Cheung, J.; Jeknavorian, A.; Roberts, L.; Silva, D. Impact of admixtures on the hydration kinetics of Portland cement. Cem. Concr. Res. 2011, 41, 1289-1309. 